\title{
Appetitive conditioning to specific times of day
}

Citation for published version (APA):

van den Akker, K., Havermans, R. C., \& Jansen, A. (2017). Appetitive conditioning to specific times of day. Appetite, 116, 232-238. https://doi.org/10.1016/j.appet.2017.05.014

Document status and date:

Published: 01/09/2017

DOI:

10.1016/j.appet.2017.05.014

Document Version:

Publisher's PDF, also known as Version of record

Document license:

Taverne

Please check the document version of this publication:

- A submitted manuscript is the version of the article upon submission and before peer-review. There can be important differences between the submitted version and the official published version of record.

People interested in the research are advised to contact the author for the final version of the publication, or visit the DOI to the publisher's website.

- The final author version and the galley proof are versions of the publication after peer review.

- The final published version features the final layout of the paper including the volume, issue and page numbers.

Link to publication

\footnotetext{
General rights rights.

- You may freely distribute the URL identifying the publication in the public portal. please follow below link for the End User Agreement:

www.umlib.nl/taverne-license

Take down policy

If you believe that this document breaches copyright please contact us at:

repository@maastrichtuniversity.nl

providing details and we will investigate your claim.
}

Copyright and moral rights for the publications made accessible in the public portal are retained by the authors and/or other copyright owners and it is a condition of accessing publications that users recognise and abide by the legal requirements associated with these

- Users may download and print one copy of any publication from the public portal for the purpose of private study or research.

- You may not further distribute the material or use it for any profit-making activity or commercial gain

If the publication is distributed under the terms of Article $25 \mathrm{fa}$ of the Dutch Copyright Act, indicated by the "Taverne" license above, 


\title{
Appetitive conditioning to specific times of day
}

\author{
Karolien van den Akker*, Remco C. Havermans, Anita Jansen \\ Faculty of Psychology and Neuroscience, Department of Clinical Psychological Science, Maastricht University, P.O. Box 616, 6200 MD Maastricht, The \\ Netherlands
}

\section{A R T I C L E I N F O}

\section{Article history:}

Received 19 June 2016

Received in revised form

4 May 2017

Accepted 5 May 2017

Available online 6 May 2017

\section{Keywords:}

Classical conditioning

Appetitive conditioning

Eating desires

Ecological momentary assessment

\begin{abstract}
A B S T R A C T
Human laboratory studies have shown that eating desires are easily learned through classical conditioning: after a few pairings of an initially neutral stimulus (e.g., a box) with the intake of palatable food (e.g., chocolate), the stimulus elicits increased eating expectancies and eating desires (acquisition). After repeated non-reinforced presentations of the chocolate-associated stimulus, eating expectancies and desires decrease again (extinction). It is commonly assumed that eating desires in daily life are acquired and extinguished in a similar manner, but to date, this has not been empirically tested. In two studies, we examined whether the repeated consumption of chocolate at a specific time of day elicits increased eating expectancies and eating desires over a period of 5 days (study 1 ) or 15 days (study 2), and relative to a time of day not paired with chocolate intake. Further, it was tested whether acquired responding diminishes again during extinction (study 1). Ecological momentary assessment was used to carry out the studies in daily life. Results showed that eating expectancies were acquired in both studies. Only in study 2 , eating desires were also successfully learned. It is concluded that eating expectancies and eating desires can be conditioned to ecologically valid cues and under real-life circumstances. This highlights the importance of associative learning processes in the experience of eating desires in daily life.
\end{abstract}

() 2017 Published by Elsevier Ltd.

\section{Introduction}

Overweight and obesity prevalence have increased dramatically over the past decades (Ogden, Carroll, Kit, \& Flegal, 2014). Experts agree that the 'obesogenic' environment plays an important role in this: it is characterized by an abundance of stimuli that signal the availability of palatable high-calorie foods, and exposure to these food cues can result in psychological and physiological changes that promote overeating (Jansen, 1998). One important psychological component of this so-called reactivity to food cues is a heightened wish or urge to consume the food, i.e., an increased desire to eat (Jansen, 1998; Kavanagh, Andrade, \& May 2005). As cue-elicited eating desires primarily concern high-calorie foods and can occur even when sated, they might easily contribute to excessive weight gain (Ferriday \& Brunstrom, 2011; Havermans, 2013; Jansen, Havermans, \& Nederkoorn, 2011). This highlights the importance of investigating the etiology of eating desires.

Cue-elicited eating desires likely have a learned component. In theory, food cues have once become associated with intake through

\footnotetext{
* Corresponding author.

E-mail address: karolien.vandenakker@maastrichtuniversity.nl (K. van den Akker).
}

repeated pairings of a stimulus (conditioned stimulus or CS) with eating (unconditioned stimulus or US) (Jansen, 1998). Upon exposure, conditioned food cues elicit conditioned appetitive responses (CRs) including a heightened desire to eat. Any cue may come to function as CS, including the sight or smell of food (Blechert, Testa, Georgii, Klimesch, \& Wilhelm, 2016), a certain emotion (Bongers \& Jansen, 2017), or a specific situation or context (van den Akker, Jansen, Frentz, \& Havermans, 2013). For example, when a person repeatedly consumes chocolate (US) in the evening, "evening time" may become a predictor (CS) for intake, subsequently eliciting an increased desire to eat (CR) (Jansen, 1998; Wardle, 1990; see also; Woods et al., 1977). Similarly, when a CS is no longer followed by the US, conditioned eating desires are expected to extinguish, and (over)eating should become less likely (Jansen et al., 2011). Findings of human laboratory conditioning studies are in line with this learning-based interpretation of cued eating desires (e.g., Bongers, van den Akker, Havermans, \& Jansen, 2015; van den Akker, Havermans, Bouton, \& Jansen, 2014; Van Gucht, Vansteenwegen, Van den Bergh, \& Beckers, 2008). These studies also suggest that eating desires are readily acquired. After only a few pairings of a stimulus (e.g., a box, vase, or tray) with the intake of food (the US; e.g., chocolate), this stimulus (CS+) usually increases eating desires relative to a stimulus not paired with food (CS-), though awareness 
of the CS-US association is likely necessary for this (i.e., reporting heightened expectancies to receive the US when presented with the CS+; van den Akker et al., 2013; Hogarth \& Duka, 2005; Birch, McPhee, Sullivan, \& Johnson, 1989). During extinction, in which the CSs are repeatedly presented but no USs are provided, US expectancies and desires both diminish - although it seems that a complete extinction of acquired eating desires is difficult to achieve (van den Akker, van den Broek, Havermans, \& Jansen, 2016; Van Gucht, Vansteenwegen, Beckers, \& Van den Bergh, 2008).

Laboratory conditioning studies are very useful to investigate the basic learning processes underlying appetitive responses to food cues. Their ultimate aim, however, is to model real-life situations. Based on the finding that arbitrary stimuli (e.g., boxes) can quickly come to function as CSs that promote eating desires, one would expect similar effects in case of more "natural" stimuli in daily life (e.g., specific times of day) that have been paired with palatable food intake. However, laboratory findings do not necessarily translate to real-life circumstances, as conditioning studies differ from everyday life in many potentially important respects. For instance, in contrast to the complex real-life world, laboratory studies are usually relatively simple and highly controlled: the participants' attention is directed to the CSs in an environment that contains very few distractors. Laboratory studies also typically use very brief intervals between subsequent CS presentations (i.e., several seconds or minutes), unusually small US sizes (e.g., one small bite of chocolate), and relatively novel cues that have received little prior exposure (e.g., a novel box). All of these factors are known to potentially affect the acquisition and extinction of conditioned responses and might decrease the ecological validity of the paradigm.

Despite these potentially important manners in which laboratory studies differ from more natural situations, to our knowledge, no published studies have investigated appetitive conditioning in daily lives and using ecologically valid cues. Therefore, the aim of the present studies was to test whether acquisition (study 1 and 2) and extinction (study 1 ) of conditioned appetitive responses can be established under real-life circumstances. In the studies, a withinsubject conditioning paradigm was implemented over the course of 17 (study 1 ) and 15 (study 2) days, using two specific times of day as CS+ and CS-. A smartphone application was used for ecological momentary assessment of US expectancies and eating desires at these time points. It was expected that differential US expectancies and eating desires would increase during an acquisition phase, and decrease again during a subsequent extinction phase.

\section{Study 1}

\subsection{Methods and materials}

\subsubsection{Participants}

27 participants completed the study. Before conducting the study, a sample size calculation on the post-acquisition differentiation in desires to eat between a CS + and a CS- of a previous study (Cohen's $d=0.69$; van den Akker, Havermans, \& Jansen, 2015). This calculation indicated that using an alpha of 0.05 and to achieve a power of $0.80, \mathrm{~N}=19$ participants would be needed. Before participation, a screening questionnaire was filled in. Participants were eligible to participate in the study if they were female undergraduate students, aged between 17 and 25, owned a wellfunctioning Android smartphone, were not currently dieting, had no allergies/intolerances for, and indicated to like, chocolate and caramel. As a cover story, participants were told the study would be about "cacao and cognitive performance". Participants received course credit or a monetary voucher worth $€ 50$, - for participation. The study was approved by the local ethical committee.

\subsubsection{Stimuli}

US: Two handmade Belgian chocolates with a caramel filling (Rousseau chocolade; approximately $30 \mathrm{~g} / 140 \mathrm{kcal}$ ) were used as US. To highlight their novelty to participants, they were introduced as "Chokito's" (this name was made-up by the researchers). Each pair of chocolates was wrapped in a non-transparent bag.

CS: Two specific times of day were used as conditioned stimuli. Prior to attending the first session, participants were asked to identify two specific times of day between 10:30 and 18:00 during which they were usually not eating or otherwise busy, and which were at least $2.5 \mathrm{~h}$ apart (e.g., 14:00 and 16:30). Whether a participant's earlier or later time point served as CS+ (chocolateassociated) or CS- (control) was counterbalanced across participants.

\subsubsection{Measurements}

US expectancy and desire to eat: $100 \mathrm{~mm}$-Visual Analogue Scales (VAS) were used to assess the expectancy to be allowed to consume the US ("How strongly do you expect to be allowed to eat Chokito's, at this moment?") and the desire to eat the US ("Pay attention to the current time of day. How strong is your desire for Chokito's, at this moment?"), ranging from 0 (I certainly do not expect it/no desire at all) to 100 (I certainly expect it/very strong desire).

US liking: 100 mm-VAS was used to assess liking of the taste of the US ("How much did you like the Chokito's?"), ranging from 0 (not at all) to 100 (very much). A 7-point Likert scale was used to assess liking of the US size ("What did you think about the size of the Chokito's?"), "1" reflecting far too little, "4" reflecting exactly right, and "7" reflecting far too much.

Compliance: a semi-structured interview was conducted to assess the participant's compliance in following the instructions. Participants were asked whether they had eaten the USs whenever asked to, and whether they had always carried at least one US during each time of day. Participants were also required to return any USs that they had not consumed. These were counted and then returned to the participant.

Revised Restraint Scale (RS; Polivy, Herman, \& Howard, 1988): To check for levels of dietary restraint (i.e. the intention to restrict food intake) the 10-item RS was used. Scores range from 0 to 35, a higher score indicating increased intentions to restrain intake.

\subsubsection{Smartphone app and trial sequence}

On all participants' mobile phones the application movisensXS, version 0.42469 (movisens GmbH, Karlsruhe, Germany) was installed. This application was personalized for each participant, triggering an auditory alarm (lasting up to $5 \mathrm{~min}$ ) on the two times of day selected by the participant. When the alarm was answered, a trial started.

\subsubsection{Design and procedure}

Participants were individually seen on two laboratory sessions, and the conditioning procedure took place in between these sessions. The personalized app was created prior to session 1 .

2.1.5.1. Session 1. On the first session, the participant gave written consent, after which she was provided with detailed oral and written instructions she was required to adhere to during the study period. On the two selected times of day, she had to make sure the sound on her phone was turned on, and she needed to have sufficient time to complete the questionnaires and to precisely follow all instructions given in the application. The participant was also required not to be eating anything or being otherwise occupied during the two times of day. Besides this, she was instructed to follow her usual eating pattern. She also had to have access to at least one Chokito package during each time of day (she thus had to 
carry two packages in case one had to be consumed at the earlier time of day). This was done to ensure that at least one US would be present during both the CS+ and CS- times of day to prevent eating desires to be increased during the $\mathrm{CS}+$ times simply because chocolate is available. Apart from this, the participant was not allowed to handle or open any of the packages. In addition, she received a plastic container to avoid damaging the chocolates when carrying them. While it was stressed that it was very important for the participant to precisely follow the instructions, she was also encouraged to indicate in the application whenever she had not been able to adhere to all instructions. To further increase compliance, the participant was informed she would receive a call from the experimenter whenever she failed to answer an alarm. Next, the personalized program was installed on the participant's phone, and she was shown an example trial sequence on a tablet computer. After this, she was explicitly instructed she would be repeatedly asked to consume one package of chocolates on one time of day, while she would never be asked to consume the chocolates on the other time of day. This instruction was modeled after laboratory conditioning studies and given to facilitate conditioning (e.g., van den Akker et al., 2015). Next, the participant was given twenty packages of the US (in order for participants not to be able to estimate the number of chocolates they would be asked to consume). It was stressed she had to return any remaining chocolates on the next session. Finally, she was asked not to discuss the study with anyone.

2.1.5.2. Conditioning procedure. All participants completed a similar seventeen-day conditioning paradigm. Auditory alarms (prompts) were triggered twice each day (i.e., on one $\mathrm{CS}+$ and one CS- time of day). The first five days of testing functioned as acquisition phase. Five $\mathrm{CS}+$ and five CS- trials were presented during this phase (for trial sequence see below), the CS + trials being followed by consumption of one US. The subsequent twelve days functioned as extinction phase during which participants received twelve CS+ and twelve CS- extinction trials (no US consumption took place).

Trial sequence: A trial started when an auditory alarm was answered, and proceeded as follows. First, the participant filled in the current time of day. This was done to direct the participant's attention towards the CS (i.e., the specific time of the day). Next, the participant rated her US expectancy. A bogus VAS regarding the participant's level of concentration was then completed. After this, she rated her desire for the US, followed by another bogus VAS (level of fatigue). Only in case of a CS + acquisition trial, the participant was now asked to open and consume one package of Chokito's. Next, two more bogus VASs (level of concentration and fatigue) were presented. This was followed by a bogus arithmetic puzzle that the participant had to finish as quickly as possible, allegedly to measure her cognitive performance. Next, the participant entered the time at which she had last eaten, was given the opportunity to write down any non-adherence to the instructions, and was asked not to eat anything within the next $30 \mathrm{~min}$ to avoid reinforcement of the CS- (and the CS+ during extinction).

2.1.5.3. Session 2. The second session took place within 1-4 days after the extinction phase. The participant completed the hypothesis awareness check and the US liking VAS. Next, the compliance interview was administered, after which the RS was filled in and the participant's length and weight were measured. The number of packages of chocolates returned by the participant was counted. The participant was thanked for participation, received her compensation, and was asked not to discuss the study with anyone.

\subsubsection{Statistical analysis}

To test whether differential US expectancies and eating desires were acquired and extinguished, 2 (CS-type: CS + vs. CS-) $\times 2$ (Day: acq1 vs. acq5/ext1 vs. ext12) repeated-measures ANOVAs were conducted, using CS-type and Day as within-subject factors. In addition, paired samples t-tests were conducted at baseline (acq1), on the last day of acquisition, and at the start (ext1) and end of extinction (ext12).

Excluding participants who did not show clear evidence for awareness of the CS-US relationship $(n=2)$ did not change the results of the analyses. Therefore, in the reported analyses, all participants were included.

\section{Results}

\subsection{Participant characteristics, missing data, and compliance}

On average, participants had a healthy BMI $(\mathrm{M}=22.65$; $\mathrm{SD}=4.22)$, and indicated a strong liking for the US $(\mathrm{M}=82.78$; $\mathrm{SD}=10.53)$ as well as a pleasant US size $(\mathrm{M}=4.22 ; \mathrm{SD}=0.80)$. Their mean age was $20.04(\mathrm{SD}=1.37)$, and their mean score on the Restraint Scale was 10.85 ( $\mathrm{SD}=3.78$ ). On average, participants received 4.63 CS-US pairings $S D=0.63)$. Some data was missing due to participants missing some of the prompts and due to technical issues. In total, data were available for 813 trials $(88.6 \%$ of all trials; $\mathrm{CS}+: 413$ trials; CS-: 400 trials).

All participants indicated having consumed the US when prompted to. Nine participants failed to return all leftover USs (1-4 USs were missing out of 15 leftover USs). When questioned about this, all but one participant stated they did not consume these USs but threw them away or must have lost them. Most participants indicated having (almost) always had access to at least one US at each time of day $(n=21 ; 77.8 \%)$; the remaining participants reported repeatedly carrying no US during the CS- $(n=3)$, or not carrying any USs as soon as they realized they were no longer asked to consume any during extinction $(\mathrm{n}=3)$.

\subsection{US expectancies and eating desires}

Mean US expectancies and eating desires for each (time of) day are presented in Fig. 1.

Participants successfully acquired US expectancies at the time of day associated with eating chocolate, as indicated by a significant CS-type $\times$ Day interaction, $F(1,17)=12.62, p=.002 .^{1}$ This resulted in a significant differentiation on the last acquisition and first extinction day: US expectancies were significantly larger in response to the CS + vs. CS-, $t(23)=9.77, p<0.001, t(21)=8.29$, $p<0.001$. Extinction of differential US expectancies was also found (CS-type $\times$ Day), $F(1,18)=29.65, p<0.001$. This extinction was not complete: on the last trial a significant difference between $\mathrm{CS}+$ and CS- expectancies was still present, $t(22)=2.47, p=0.02$.

In contrast, we failed to find evidence for an acquisition of the desire to eat (CS-type $\times$ Day), $F<1$. Unsurprisingly then, no differential desire to eat was present on the last acquisition day, $t(23)=1.00, p=0.33$, nor on the first extinction day, $t(21)=1.43$, $p=0.17$. Since a conditioned response cannot be extinguished if not first acquired, extinction of eating desires was not tested.

In sum, while expectancies were successfully acquired and (partially) extinguished, eating desires did not show this pattern. This is in contrast to findings of laboratory conditioning studies which generally report a successful acquisition of desires after a similar amount of pairings between a stimulus and a US, provided that differential US expectancies were successfully acquired.

\footnotetext{
${ }^{1}$ Degrees of freedom vary across analyses due to missing data.
} 


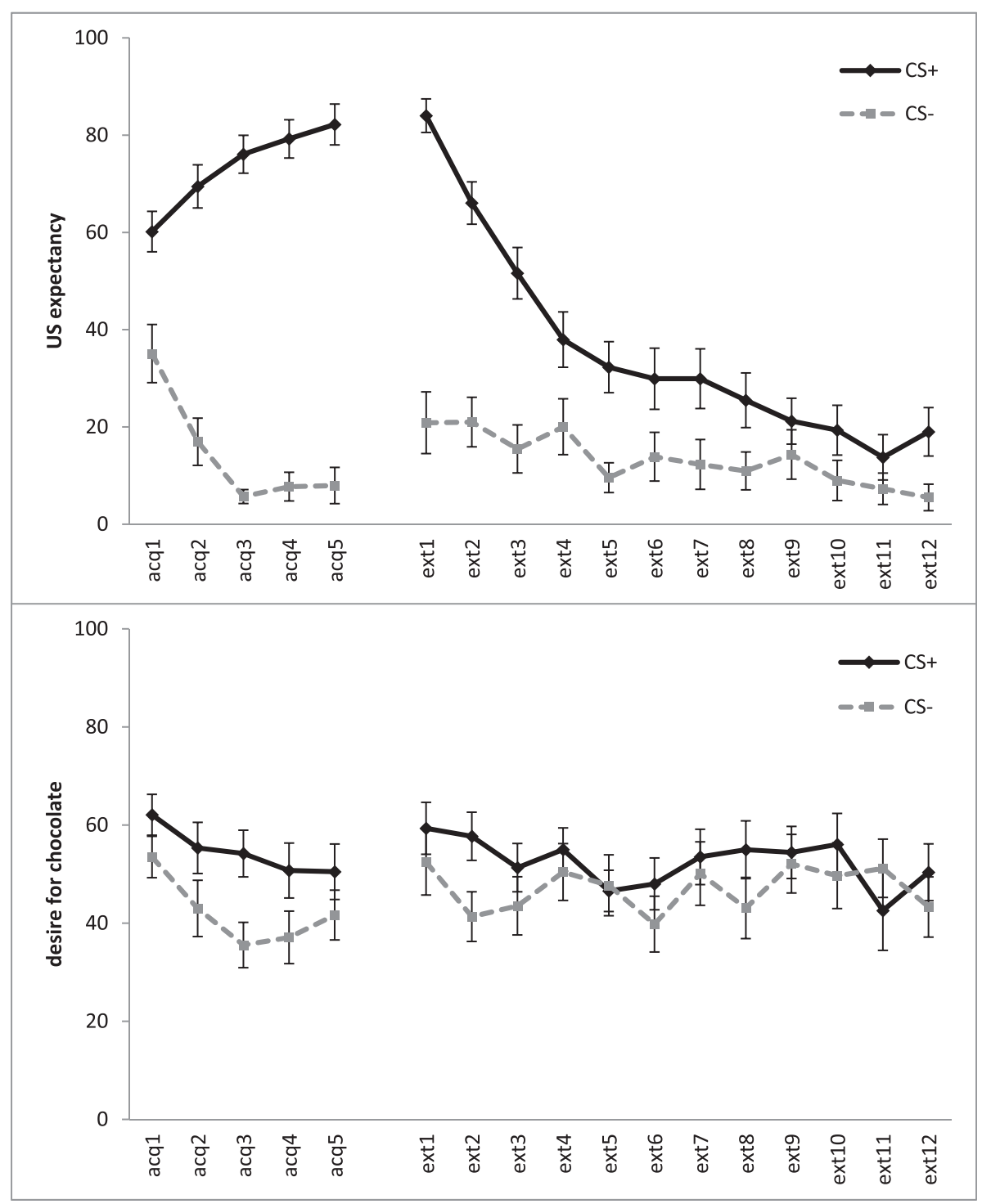

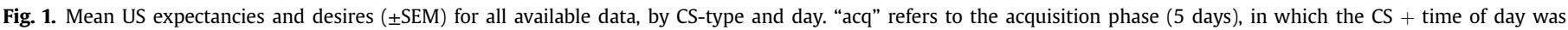
repeatedly paired with eating chocolate. "ext" refers to the extinction phase (12 days), during which no more chocolate was consumed.

\section{Discussion}

The current study examined whether eating expectancies and desires can be learned and extinguished using a differential conditioning paradigm implemented in real-life and using ecologically valid cues as CSs (two different times of day). It was found that whereas US expectancies were successfully acquired, eating desires were not.

The finding that overall, eating desires were not successfully acquired despite a successful acquisition of US expectancies seems in contrast to findings of laboratory studies (e.g., van den Akker et al., 2013; Van Gucht, Vansteenwegen, Beckers, et al., 2008; for an overview, see Jansen, Schyns, Bongers, \& van den Akker, 2016). In these studies, a few CS-US pairings are usually sufficient to establish conditioned eating expectancies and desires, a recent study even showing conditioned responding after a single CS-US pairing (Blechert et al., 2016). Thus, the present findings might suggest that the relative ease of acquisition of conditioned eating desires usually seen in laboratory studies does not translate to the acquisition of eating desires in real-life.
It might however be that eating desires can be acquired in reallife but more CS-US pairings are necessary. For example, as mentioned in the introduction, acquisition of appetitive responding in real-life vs. the laboratory could be slowed due to a more distracting environment, or due to a participant's extensive history with (non-reinforcement of) the CSs. It is also possible that the nature of the stimuli used in the present study slowed acquisition: time of day is a relatively diffuse stimulus, compared with the more distinct and salient stimuli used in laboratory conditioning studies. Such diffuse stimuli may require more pairings with food for eating desires to develop.

It may also be that a smaller US size will result in a successful acquisition of eating desires: although participants experienced, on average, the US size as pleasant, several participants $(n=8)$ reported the US to be (slightly) too large, possibly rendering the US somewhat aversive for these participants. This could have interfered with acquisition.

Finally, in line with visual inspection of Fig. 1, an overall decline in eating desires was present over the course of acquisition, $F(1$, $17)=6.53, p=0.02$. One possible explanation for this is that eating 
desires were heightened on the first acquisition day because participants were looking forward to tasting the chocolates they were shown on the first session. It may be that without knowledge about the nature of the US prior to acquisition a more accurate baseline assessment of eating desires can be obtained.

Thus, the findings seem to suggest that eating desires are not easily acquired under naturalistic circumstances. However, it may be that implementing some changes to the study design results in a successful acquisition of eating desires.

\section{Study 2}

\subsection{Introduction}

The aim of study 2 was to test whether a successful acquisition of eating desires in real-life can be achieved with some changes to the study design. The acquisition phase was lengthened considerably (15 days), and a smaller US was used (one chocolate instead of two). Participants were also no longer shown the USs nor told about their nature prior to acquisition.

\subsection{Methods and materials}

\subsubsection{Participants}

33 participants completed the study. Four additional participants started the study but dropped out due to technical problems. Similar inclusion criteria as in study 1 were used. Because no more information was provided regarding the nature of the US prior to acquisition, as a cover story, participants were now informed the study would be about "biorhythm and cognitive performance". Participants received course credit or a monetary voucher worth $€$ 40, - for participation.

\subsubsection{Stimuli}

The US was similar to the one used in study 1, except that participants now received one chocolate (approximately $15 \mathrm{~g} / 70 \mathrm{kcal}$ ) instead of two. It was introduced as a "Chokito" via the smartphone app when the participant had to consume it for the first time. Until then, the US was simply referred to as "a package". The criteria for the times of day (CSs) and their randomization were similar to Study 1 .

\subsubsection{Measurements}

Measures were similar to those used in study 1, except that on the first acquisition day only, the expectancy ("How strongly do you expect to be allowed to eat the contents of a package, at this moment?") and desire to eat VAS ("Pay attention to the current time of day. How strong is your desire to eat something tasty, at this moment?") were framed differently (i.e., without mentioning 'Chokito'). The anchors were the same as in study 1. Further, the remaining US expectancy VASs now referred to "a Chokito" instead of "Chokito's". Finally, to check whether the daily consumption of the US results in a decreased US liking over time (which might interfere with acquisition), we included a 5-point Likert scale that retrospectively asked about any change in liking of the US over the study period ('Did your liking of the Chokito's change over time?'), "1" reflecting 'Yes, my liking of the Chokito's increased a lot', '3' reflecting 'no, my liking of the Chokito's remained the same', and ' 5 ' reflecting 'Yes, my liking of the Chokito's decreased a lot'.

\subsubsection{Smartphone app}

MovisensXS version 1.0.0 was used. Prompts were given in the same way as in study 1 .

\subsubsection{Design and procedure}

The design and procedure of the study was similar to study 1 , with a few exceptions. Participants now completed 15 acquisition days ( 15 CS + trials and 15 CS- trials), and no extinction phase was included because the aim of this second study was to test the acquisition of eating desires. Further, during a trial, the bogus VASs used in study 1 were no longer administered. During the second laboratory session, 'change in US liking' was additionally assessed.

\subsubsection{Statistical analysis}

Statistical analyses were similar to those conducted for study 1 .

\section{Results}

\subsection{Participant characteristics, missing data, and compliance}

The mean BMI of the participants was 22.96 (SD = 3.46). On average, participants indicated a strong liking for the US $(\mathrm{M}=84.44 ; \mathrm{SD}=15.57)$ that remained relatively stable during the study period $(\mathrm{M}=3.18, \mathrm{SD}=0.88)$. They rated the size of the US as pleasant $(\mathrm{M}=3.76$; $\mathrm{SD}=0.66)$. The mean score on the Restraint Scale was $11.27(\mathrm{SD}=4.69)$. On average, participants received 13.30 CS-US pairings $(S D=1.74)$. Data was available for 888 trials $(89.7 \%$ of all trials; CS+: 439 trials; CS-: 449 trials).

Participants reported having always consumed the US when prompted to, except when feeling ill $(n=1)$ or when the US was currently not available $(n=1)$. Fifteen participants did not return all leftover USs. However, none of the participants indicated having consumed any of these missing USs. Most participants indicated having had access to a US on each time of day $(n=28 ; 84.9 \%)$. The remaining participants reported carrying no US during the CS- for one or two days $(n=4)$, or for almost the entire study period $(\mathrm{n}=1)$.

\subsection{US expectancies and eating desires}

Mean US expectancies and eating desires for each (time of) day are shown in Fig. 2.

US expectancies were again successfully acquired: differential expectancies increased from the first to the last acquisition day (CStype $\times$ Day interaction), $F(1,24)=160.86, p<0.001$, and on the last day, participants reported significantly greater expectancies to be allowed to eat the US at the CS + (vs. CS-) time of day, $t(28)=51.16$, $p<0.001$.

In contrast to study 1 , eating desires were now successfully conditioned to the time of day associated with eating chocolate. This was evidenced by a significant CS-type $\times$ Day interaction, $F(1$, $24)=15.40, p=0.001$, indicating that chocolate desires to the $\mathrm{CS}+$ vs. CS- increased over the course of acquisition. This resulted in significantly larger desires to the CS + vs. CS- on the last acquisition day, $t(28)=6.40, p<0.001$. Further, acquisition was characterized by significant reductions in desires to the CS- from the first to the last trial, $t(26)=3.68, p=0.001$, and a trend towards larger desires to the $\mathrm{CS}_{+}, t(27)=-1.74, p=0.09$. Finally, in line with visual inspection of the data, a significant CS + vs. CS- differentiation was present by day $4, t(29)=2.60, p=0.015$.

\section{Discussion}

In study 2, we implemented some changes to the study design most notably, a larger number of acquisition trials and a smaller US - to test whether this would result in a successful acquisition of eating desires. Results indeed clearly indicated the development of both eating expectancies and eating desires to a specific time of day that was repeatedly paired with eating chocolate. Eating desires 


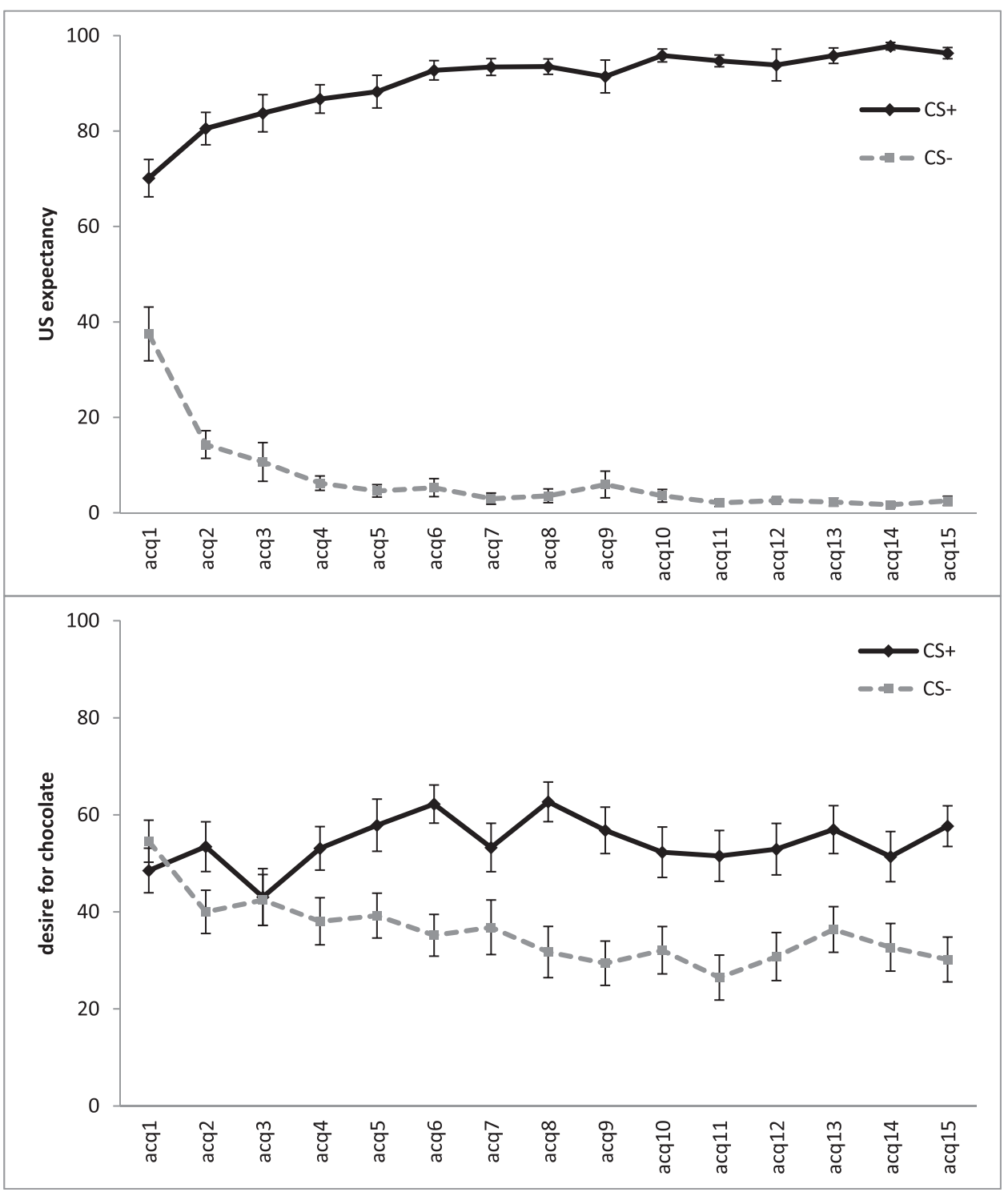

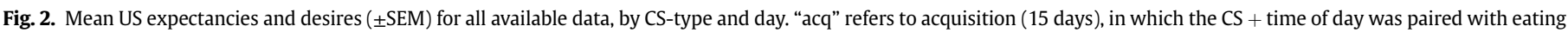

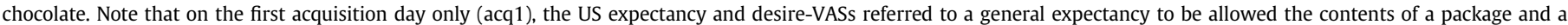
general desire for something tasty.

were heightened during the CS + vs. CS- time of day by acquisition day 4 .

To our knowledge, this work represents the first effort to condition eating expectancies and desires under real-life circumstances, and hence, to empirically test the assumption that naturalistic stimuli in daily life can become desire-evoking appetitive CSs after repeated CS-US pairings (e.g., Bouton, 2011; Jansen et al., 2011; see also; Woods et al., 1977). The findings highlight the importance of associative learning processes in the experience of eating desires in daily life, and in addition, lend support to the ecological validity of the laboratory conditioning paradigm. Interestingly, and largely comparable to findings of laboratory studies, the current data also suggest that a successful acquisition of eating desires in real-life can - at least under certain circumstances already occur after relatively few CS-US pairings. This makes sense from an evolutionary perspective: a quick acquisition of desires to stimuli that predict (tasty) food availability minimizes the chance to miss an eating opportunity.

Of note, one could argue that instead of time of day, some routinized aspect of a participant's life that co-occurred with the $\mathrm{CS}+$ time of day (such as finishing a certain daily activity) actually functioned as the CS+. However, since CSs were selected based on certain times of day (and not certain activities), it seems more plausible that time of day was the discriminative cue. Further, the differential desires that were acquired (i.e., increased desires to the CS + vs CS- over acquisition) seemed primarily due to a reduction in responding to the CS-. Although comparing responses between a CS + and CS- allows controlling for non-associative processes (e.g., overall changes in eating desires), this finding suggests that conditioned inhibition to the CS- may be at least partly responsible for the acquired differentiation (Lissek et al., 2005). However, even if inhibition to the CS- contributed substantially to the current effects, the data would still demonstrate that eating desires in reallife can be influenced by prior learning experiences. Future research may aim to further examine the relative contributions of excitation to the CS+ and inhibition to the CS- to the differential acquisition of eating desires.

In sum, the current data provide evidence that both eating 
expectancies and eating desires can be conditioned to ecologically valid cues (times of day) and under real-life circumstances. Extinction patterns of naturalistically conditioned eating desires await investigation.

\section{Acknowledgements}

These studies were financed by the Netherlands Organisation for Scientific Research (NWO; Vici Grant 453.10.006, awarded to Anita Jansen). The authors would like to thank Anastacia de Graaff and Angelina Haberhausen for their help in carrying out the studies.

\section{References}

Birch, L. L., McPhee, L., Sullivan, S., \& Johnson, S. (1989). Conditioned meal initiation in young children. Appetite, 13(2), 105-113. http://dx.doi.org/10.1016/01956663(89)90108-6.

Blechert, J., Testa, G., Georgii, C., Klimesch, W., \& Wilhelm, F. H. (2016). The Pavlovian craver: Neural and experiential correlates of single trial naturalistic food conditioning in humans. Physiology \& Behavior, 158, 18-25. http://dx.doi. org/10.1016/j.physbeh.2016.02.028.

Bongers, P., \& Jansen, A. (2017). Emotional eating and Pavlovian learning: Evidence for conditioned appetitive responding to negative emotional states. Cognition and Emotion, 1-14. http://dx.doi.org/10.1080/02699931.2015.1108903.

Bongers, P., van den Akker, K., Havermans, R., \& Jansen, A. (2015). Emotional eating and Pavlovian learning: Does negative mood facilitate appetitive conditioning? Appetite, 89, 226-236. http://dx.doi.org/10.1016/j.appet.2015.02.018.

Bouton, M. E. (2011). Learning and the persistence of appetite: Extinction and the motivation to eat and overeat. Physiology \& Behavior, 103(1), 51-58. http://dx. doi.org/10.1016/j.physbeh.2010.11.025.

Ferriday, D., \& Brunstrom, J. M. (2011). 'I just can't help myself': Effects of food-cue exposure in overweight and lean individuals. International Journal of Obesity, 35(1), 142-149.

Havermans, R. C. (2013). Pavlovian craving and overeating: A conditioned incentive model. Current Obesity Reports. http://dx.doi.org/10.1007/s13679-013-0053-z.

Hogarth, L., \& Duka, T. (2005). Human nicotine conditioning requires explicit contingency knowledge: Is addictive behaviour cognitively mediated? Psychopharmacology, 184(3), 553-566. http://dx.doi.org/10.1007/s00213-005-0150-0.

Jansen, A. (1998). A learning model of binge eating: Cue reactivity and cue exposure. Behaviour Research and Therapy, 36(3), 257-272. http://dx.doi.org/10.1016/ S0005-7967(98)00055-2.

Jansen, A., Havermans, R. C., \& Nederkoorn, C. (2011). Cued overeating. In
V. R. Preedy, R. R. Watson, \& C. R. Martin (Eds.), Handbook of behavior, food and nutrition. New York: Springer.

Jansen, A., Schyns, G., Bongers, P., \& van den Akker, K. (2016). From lab to clinic: Extinction of cued cravings to reduce overeating. Physiology \& Behavior, 162 174-180. http://dx.doi.org/10.1016/j.physbeh.2016.03.018.

Kavanagh, D. J., Andrade, J., \& May, J. (2005). Imaginery relish and and exquisite torture: The elaborated intrusion theory of desire. Psychological Review, 112 446-467. http://dx.doi.org/10.1037/0033-295X.112.2.446.

Lissek, S., Powers, A. S., McClure, E., Phelps, E. A., Woldehawariat, G., Grillon, C., et al. (2005). Classical fear conditioning in the anxiety disorders: A meta-analysis. Behaviour Research and Therapy, 43, 1391-1424. http://dx.doi.org/10.1016/ j.brat.2004.10.007.

Ogden, C. L., Carroll, M. D., Kit, B. K., \& Flegal, K. M. (2014). Prevalence of childhood and adult obesity in the United States, 2011-2012. JAMA, 311(8), 806-814. http://dx.doi.org/10.1001/jama.2014.732.

Polivy, J. Herman, C. P. \& Howard, K. (1988). The restraint Scale: Assessment of dieting. In M. Hersen, \& S. Bellack (Eds.), Dictionary of behavioural assessment techniques (pp. 377-380). New York: Pergamon.

van den Akker, K., Havermans, R. C., Bouton, M. E., \& Jansen, A. (2014). How partial reinforcement of food cues affects the extinction and reacquisition of appetitive responses. A new model for dieting success? Appetite, 81, 242-252. http://dx. doi.org/10.1016/j.appet.2014.06.024.

van den Akker, K., Havermans, R. C., \& Jansen, A. (2015). Effects of occasiona reinforced trials during extinction on the reacquisition of conditioned responses to food cues. Journal of Behavior Therapy and Experimental Psychiatry, 48, 50-58. http://dx.doi.org/10.1016/j.jbtep.2015.02.001.

van den Akker, K., Jansen, A., Frentz, F., \& Havermans, R. C. (2013). Impulsivity makes more susceptible to overeating after contextual appetitive conditioning. Appetite, 70, 73-80. http://dx.doi.org/10.1016/j.appet.2013.06.092.

van den Akker, K., van den Broek, M., Havermans, R. C., \& Jansen, A. (2016). Violation of eating expectancies does not reduce conditioned desires for chocolate. Appetite, 100, 10-17. http://dx.doi.org/10.1016/j.appet.2016.02.004.

Van Gucht, D., Vansteenwegen, D., Beckers, T., \& Van den Bergh, O. (2008). Return of experimentally induced chocolate craving after extinction in a different context: Divergence between craving for and expecting to eat chocolate. Behaviour Research and Therapy, 46(3), 375-391. http://dx.doi.org/10.1016/j. brat.2008.01.003.

Van Gucht, D., Vansteenwegen, D., Van den Bergh, O., \& Beckers, T. (2008). Conditioned craving cues elicit an automatic approach tendency. Behaviour Research and Therapy, 46(10), 1160-1169. http://dx.doi.org/10.1016/j.brat.2008.05.010.

Wardle, J. (1990). Conditioning processes and cue exposure in the modification of excessive eating. Addictive Behaviors, 15, 387-393. http://dx.doi.org/10.1016/ 0306-4603(90)90047-2.

Woods, S. C., Vasselli, J. R., Kaestner, E., Szakmary, G. A., Milburn, P., \& Vitiello, M. V. (1977). Conditioned insulin secretion and meal feeding in rats. Journal of Comparative and Physiological Psychology, 91, 128-133. http://dx.doi.org/ 10.1037/h0077307. 